\title{
Erratum to: Simulation and bench studies of the constructively and technologically modernized high performance piston aircraft engine. Stage I
}

\author{
W. OSTAPSKI ${ }^{1 *}$, T. WIERZCHOŃ${ }^{2}$, J. RUDNICKI ${ }^{2}$, and S. DOWKONTT ${ }^{1}$ \\ ${ }^{1}$ Institute of Machine Design Fundamentals, Warsaw University of Technology, 84 Narbutta St., 02-524 Warsaw, Poland \\ ${ }^{2}$ Faculty of Materials Science and Engineering, Warsaw University of Technology, 141 Wołoska St., 02-507 Warsaw, Poland
}

\begin{abstract}
In Ostapski et al., Bull. Pol. Ac.: Tech 65(1), 93-105 (2017), doi: 10.1515/bpasts-2017-0012, an analysis of tribological wear of an assembly composed of cylinder liner and piston rings in a piston aircraft engine was presented. In place of the previously used technology of gas nitriding of the cylinder liner (made out of 38CrAlMo6-10 steel), formation of multi-component or composite layers by nitriding in plasma discharge environment was proposed. Also, a modification of the previously used chromium coating of the piston rings by plasma nitriding was proposed. A study on the structure and properties of surface layer diffusion manufactured by utilizing the phenomenon of cathode sputtering was carried out. Wear resistance tests were performed on a specially designed bench, with the use of isotope markers. Verification of each of the friction couples was based on using the wear of the ring as a function of the distance trip, and the roughness of the cylinder liner and ring. This note corrects flaws in illustrations published in the original paper.
\end{abstract}

Key words: aircraft, piston, engine, plasma, nitriding.

\section{Erratum}

In the original paper sent to the editor, the authors mistakenly placed illustrations (Figs. 3-13) containing an incorrect linear scale. Illustrations with the correct scale are provided below. The authors apologize readers for this error.

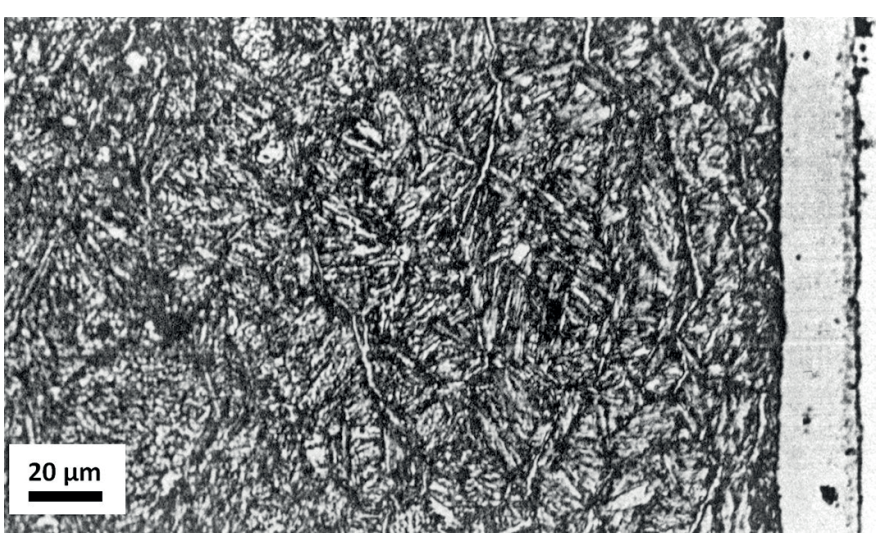

Fig. 3. The microstructure of nitrided layers of the nitride diffusion zone $\left(\mathrm{Fe}_{2-3} \mathrm{~N}+\mathrm{Fe}_{4} \mathrm{~N}\right)$

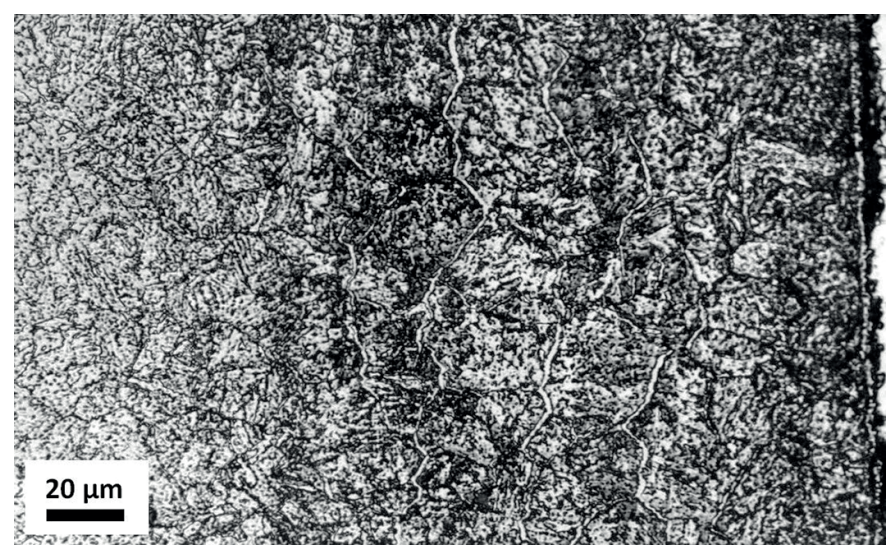

Fig. 4. The microstructure of nitrided layers of diffusion without the nitride diffusion zone

*e-mail: wos@simr.pw.edu.pl 


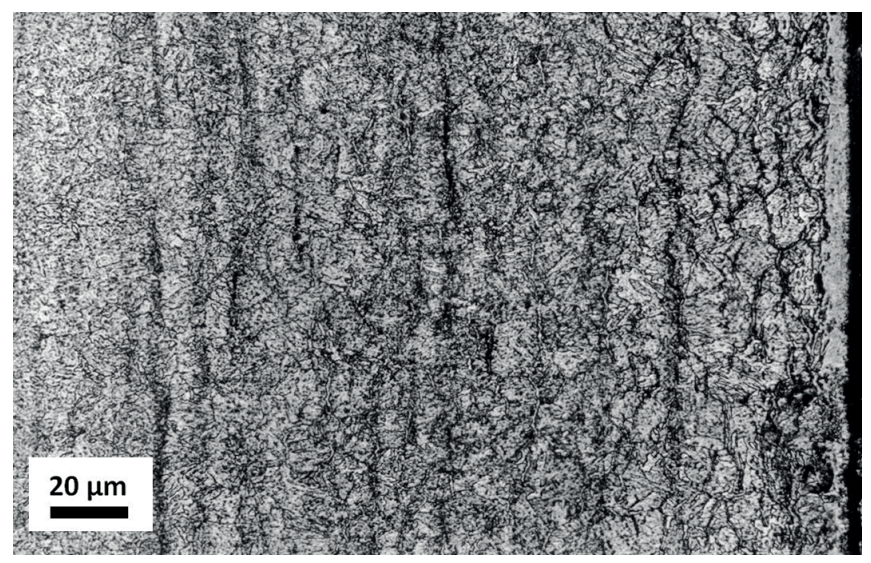

Fig. 5. The microstructure of nitrided layers of oxygen diffusion

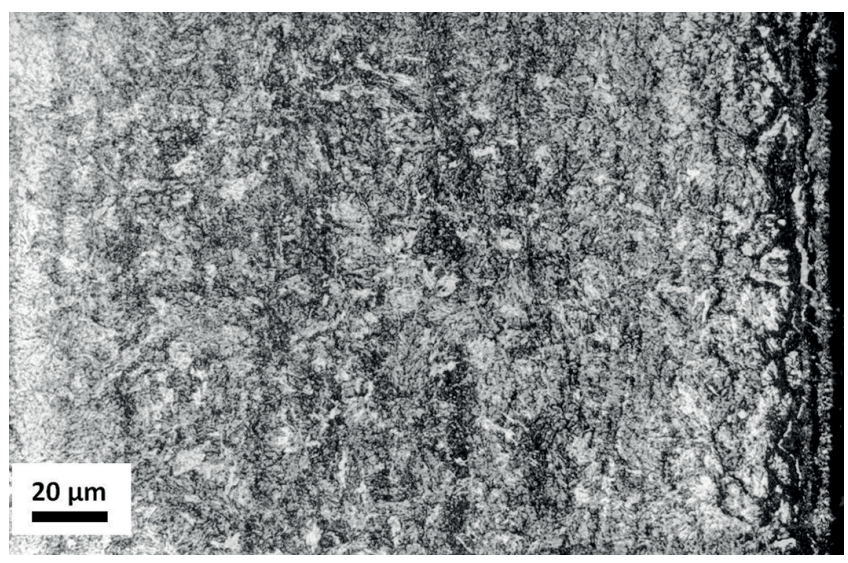

Fig. 6. The microstructure of nitrided layers of oxygen diffusion

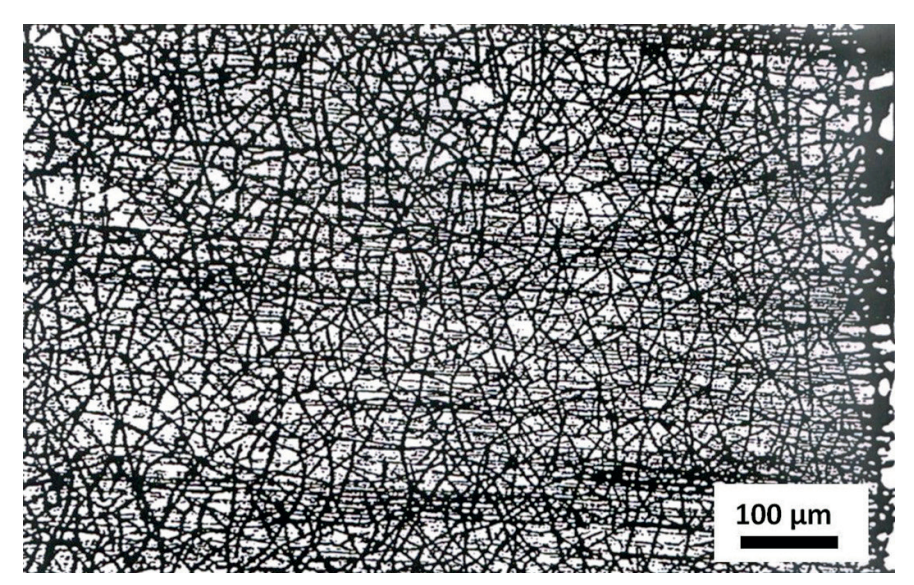

Fig. 7. Grid cracks on the surface of the chromium coating on a ring made of ductile iron

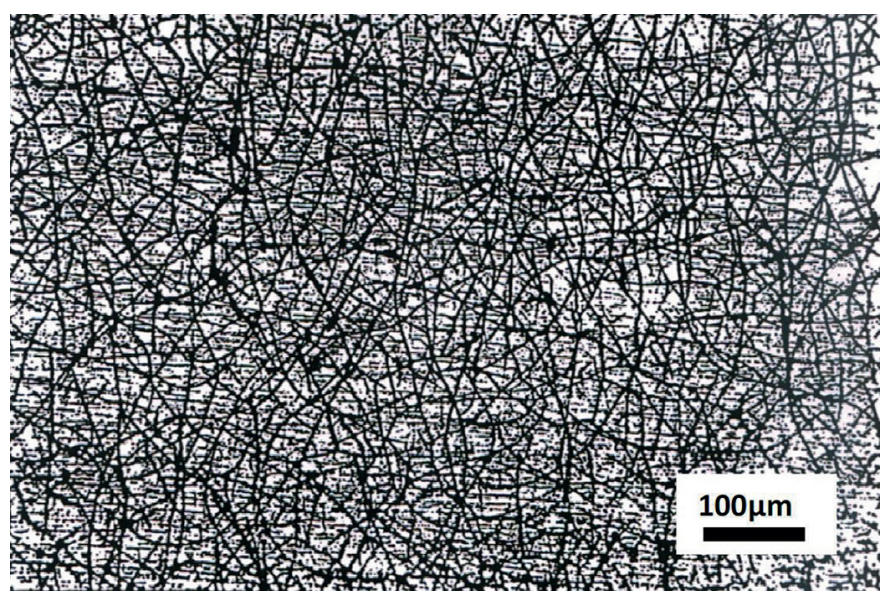

Fig. 8. Grid cracks on the surface of the chromium coating on a H12MF steel ring

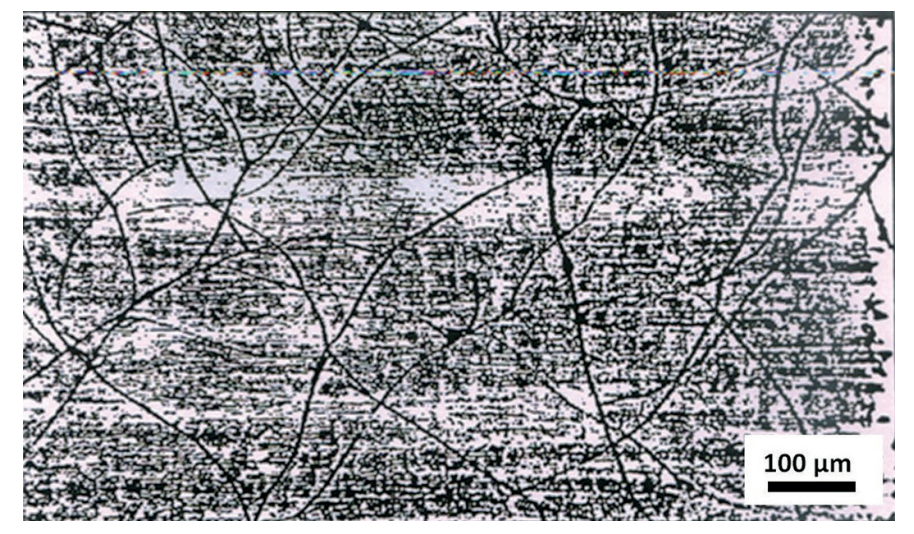

Fig. 9. Grid cracks on the surface of the chromium coating on a H12MF steel ring (zoom)
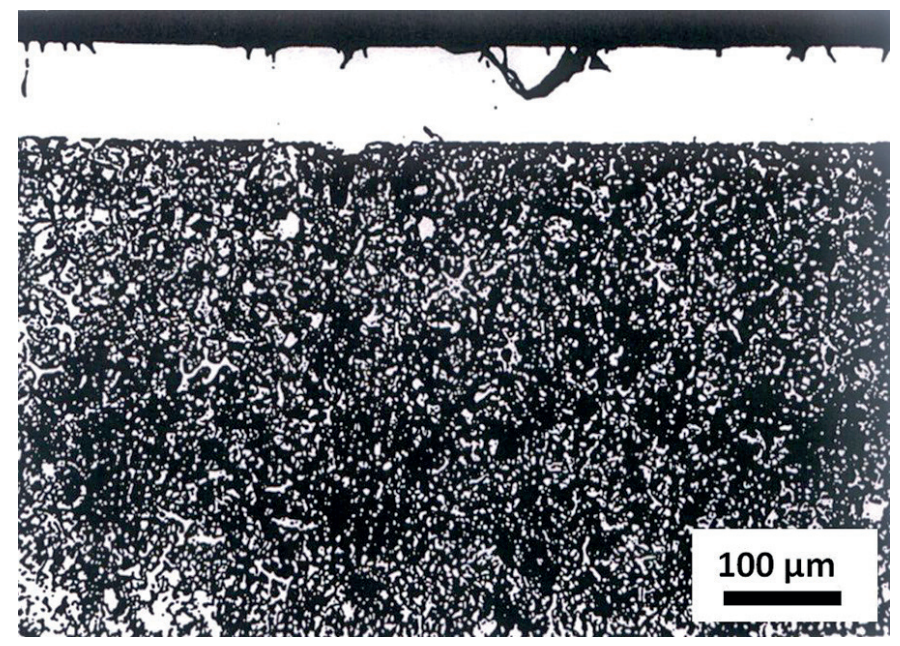

Fig. 10. The microstructure layer of chrome - a large network of cracks (transverse metallographic section) on a ring made of ductile iron 


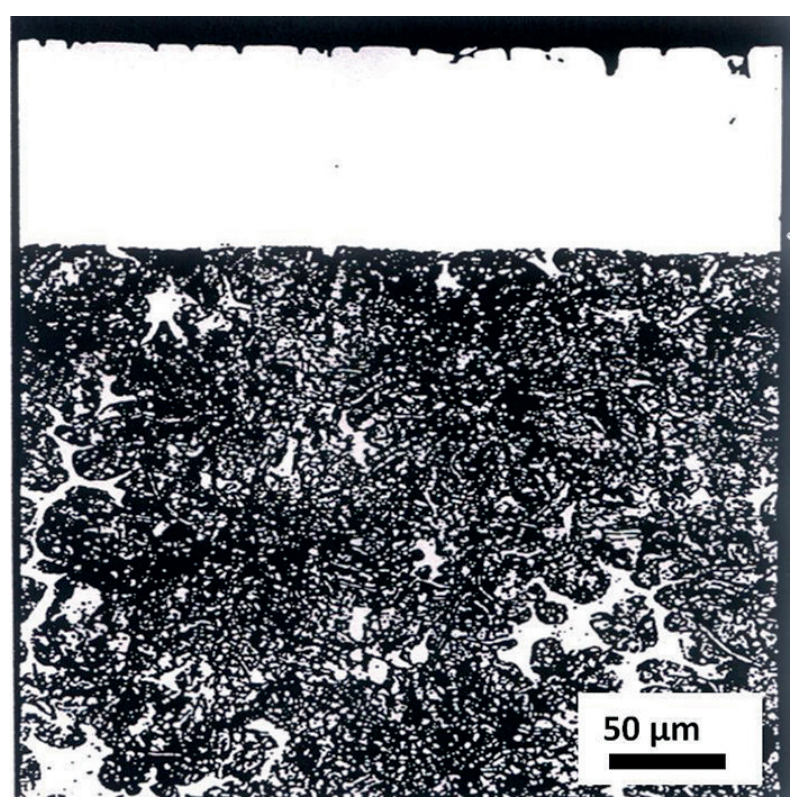

Fig. 11. The microstructure of chrome layers - a dense network of cracks (transverse metallographic section) on a ring made of ductile iron

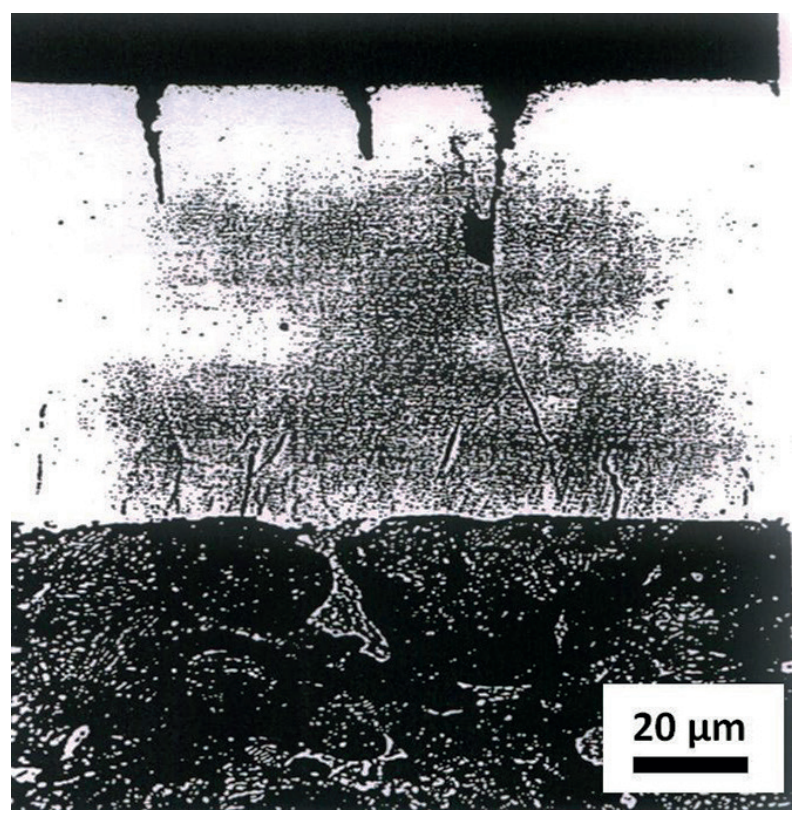

Fig. 12. The microstructure layer of chromium - a large network of cracks (transverse metallographic section) on a ring made of ductileiron

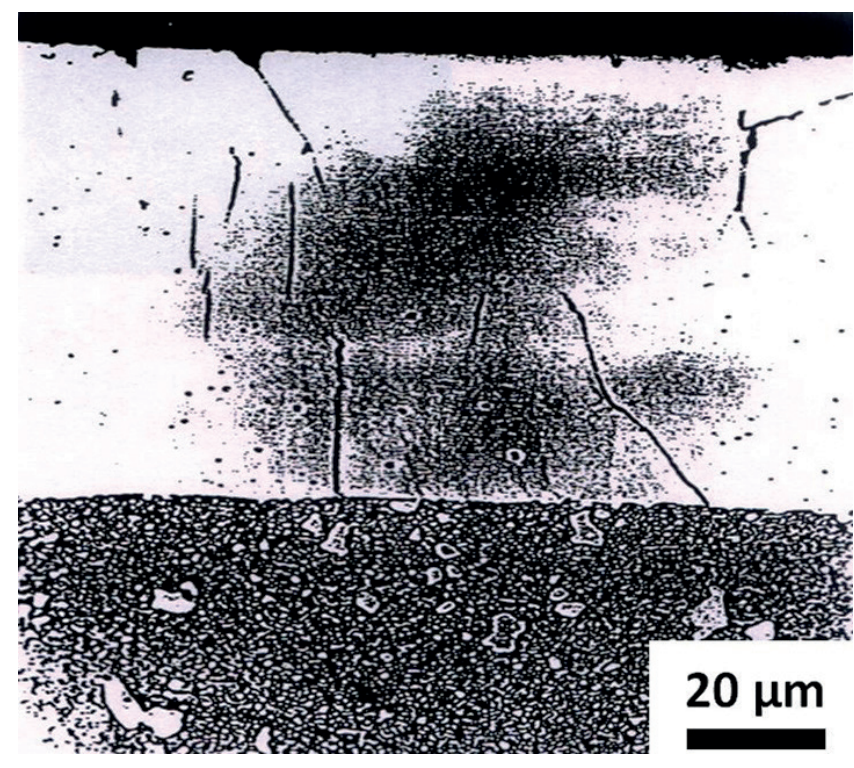

Fig. 13. The microstructure of the chromium layer - a large network of cracks (transverse metallographic section) on a H12MF steel ring 